\title{
Efficacy of Steroid Therapy on Liver Metastasis of Thymic Carcinoid
}

\author{
Ryoichi Hayashi, Norinao Hanyu and Shin-ichi Moriyama*
}

\begin{abstract}
We present a 61-year-old man who was hospitalized because of dyspnea, abdominal pain and liver dysfunction accompanied by ascites due to hepatic metastasis of a thymic carcinoid 20 years after the primary tumor was excised. His symptoms and liver function were well controlled by prednisolone, 30 to $60 \mathrm{mg}$ daily, for the next 2 years, with a reduction in the size of the hepatic tumors and in the accumulation of ascites. He subsequently contracted pneumonia due to methicillinresistant staphylococci, developed disseminated intravascular coagulation (DIC) and died. Thus, prednisolone should be considered for treating patients with metastasis of a thymic carcinoid. (Internal Medicine 33: 45-47, 1994)
\end{abstract}

Key words: thymic carcinoid, liver tumors, liver dysfunction, ascites, steroid therapy

\section{Introduction}

Thymic carcinoid is a rare tumor that tends to recur and metastasize many years after the initial diagnosis and treatment (1-3). Excision of the tumor and subsequent radiation therapy is the treatment of choice (4-6). In some cases, it is difficult to excise the original or metastatic tumors, particularly if they are extrathoracic metastatic tumors. We present the case of a patient with liver metastasis of a thymic carcinoid whose symptoms and liver dysfunction improved during steroid administration.

\section{Case Report}

A 61-year-old man was admitted to our hospital in March 1988 because of severe dyspnea and abdominal pain. Breath sounds were diminished over both lower lobes with fine crackles. His liver was enlarged, with abnormal liver function and ascites. A detailed review of his history revealed that in 1964 when he was 37-year-old, a small coin-shaped lesion was observed at the right hilus during a routine chest X-ray. This lesion was diagnosed as a benign tumor, as it had also been noted 4 years earlier. However, a follow-up X-ray one year later showed that the tumor had grown to the size of a fist $(8 \mathrm{~cm})$. Histopathologic examination of the specimen obtained during surgery revealed a thymic carcinoid; radical thoracotomy was performed with excision of the lymph nodes of the neck. The patient received postoperative radiation therapy (Liniac $90 \mathrm{~Gy}$ ) and did well until March 1977, when he complained of a sensory disturbance in his left foot and difficulty in walking and urinating. The results of roentgenographic studies, including a chest X-ray, myelography and a scintigram performed at the Shinshu University School of Medicine, led to a diagnosis of radiation myelopathy and pulmonary fibrosis. The physical condition of the patient was good, except for symptoms or signs associated with radiation myelopathy, for the next 4 years. He then developed pneumonia in May 1984. A chest X-ray showed right lower pleural effusion that did not completely disappear despite antibiotic therapy. His symptoms of dyspnea and abdominal pain gradually worsened over the next 4 years, with an increase in pleural effusion accompanied by hepatomegaly, ascites and liver dysfunction.

On admission, the pneumonia improved after antibiotic therapy. However, the dyspnea and abdominal pain accompanied by ascites and pleural effusion worsened. Ultrasound of the liver showed multiple hyperechoic masses. A liver biopsy was performed to examine the tumors. The histological findings of the biopsy were almost the same as those of the primary mediastinum tumor, that is, relatively small and uniform epithelial cells with hyperchromatic round nuclei proliferating in a sheet-like fashion or in solid-cell nests, partly accompanied by palisading arrangements of cuboidal cells at their peripheries (Fig. 1). Many chromogranins A-positive cells were immunohistochemically indicated in some parts of the tumor tissues (Fig. 2), although Grimelius and Fontana-Masson stains were both negative. These cells showed no immunoreactivity to

From the Department of Neurology, Pathology*, Nagano Red Cross Hospital, Nagano

Received for publication June 16, 1993; Accepted for publication November 26, 1993

Reprint requests should be addressed to Dr. Ryoichi Hayashi, the Division of Clinical Neurophysiology, School of Allied Medical Science, Shinshu University, Matsumoto 390 


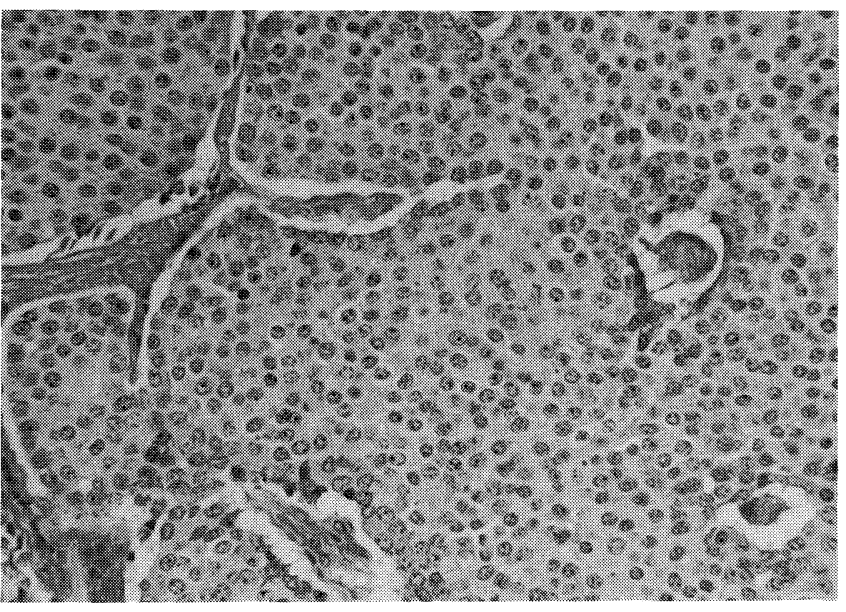

Fig. 1. Micrograph of a section of the biopsied liver tumor, original magnification $\times 270$. The tumor was composed of small, uniform epithelial cells (HE).

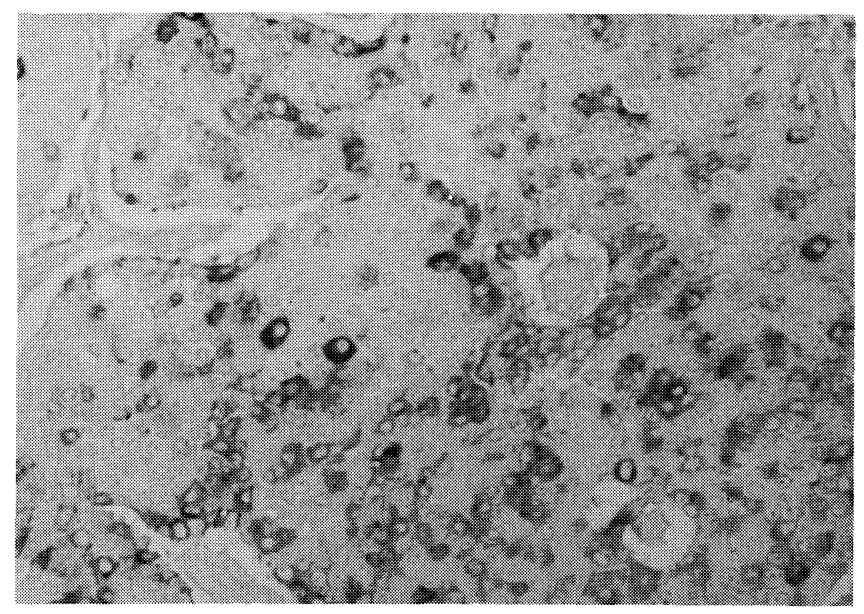

Fig. 2. Micrograph of a serial section of Fig. 1. Numerous chromogranins A-positive tumor cells are seen (PAP method, $\times 270$ ).

serotonin, cytokeratin and Leu 7. Based on these pathological findings, the liver tumors were diagnosed as metastatic tumors from the thymic carcinoid.

The tumors were determined by surgeons to be inoperable. The patient was then placed on oral prednisolone, $60 \mathrm{mg}$ daily to start and then later $30 \mathrm{mg}$ daily. During this treatment course, the dyspnea and abdominal pain gradually improved. In addition, the number and mass size of the tumors, the pleural effusion and the ascites decreased. Liver function also improved. For 10 months, the dyspnea and abdominal pain were well controlled. Then beginning in June 1989, the patient complained of severe abdominal pain. Ultrasound of the liver showed an increase in the number and size of the masses (Fig. 3 ). His liver gradually began to enlarge; its edge could be felt $8 \mathrm{~cm}$ below the right costal margin in November 1989. Intrave-
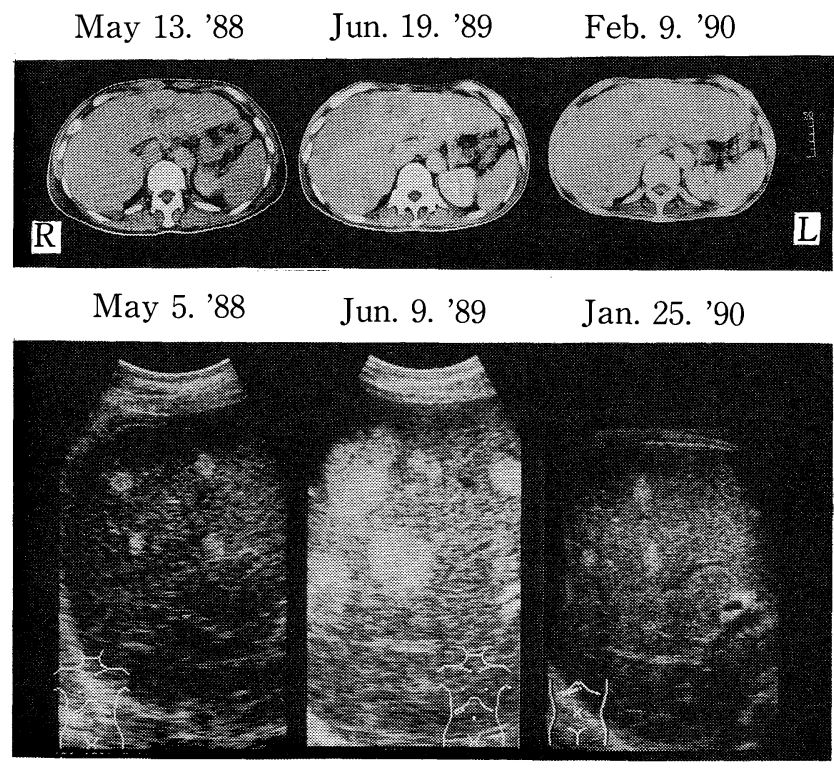

Fig. 3. Abdominal computed tomography and liver ultrasonogram in 1988, 1989 and 1990. Multiple liver lesions observed in June 1989 were reduced in size during treatment with prednisone.

nous infusion of methylprednisolone, $1,000 \mathrm{mg}$ daily for 3 days, led to an improvement in both the ascites and liver function, and the liver lesions decreased in size (Fig. 3). Oral prednisolone, 40 $\mathrm{mg}$ daily, was then administered. Liver function improved for a few months after the treatment with methylprednisolone and prednisolone. However, his liver gradually enlarged again causing abdominal pain; the abdominal pain was controlled with morphine. The patient subsequently developed pneumonia due to methicillin-resistant staphylococci and disseminated intravascular coagulation (DIC), and died on July 1, 1990, at the age of 63. His laboratory findings and other data collected between January 1988 and July 1990 are summarized in Fig. 4.

In the postmortem examination, a scar-like fibrosis was noted in the anterosuperior mediastinum; local recurrence of disease was not detected. Hematogeneous tumor metastases were spread widely to the liver, spleen, heart, lungs, kidneys, and vertebral bones. Diffuse proliferation of small bean-sized tumor nodules was visible in the enormously swollen liver which weighed 5,300 g, with evidence of hemorrhage and necrosis. The histological and histochemical findings of the liver tumors, observed in ultrasound studies and the computed tomographic studies and in other lesions, were almost the same as those of the liver biopsy done in 1988.

\section{Discussion}

This case of thymic carcinoid was characterized by liver metastases occurring 20 years after the initial diagnosis and excision, and the improvement of clinical symptoms and a reduction in the metastatic lesions of the liver after steroid therapy. 


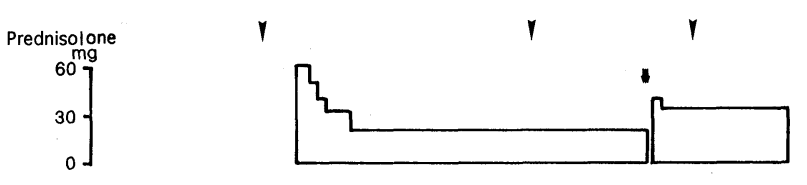

Abdomen
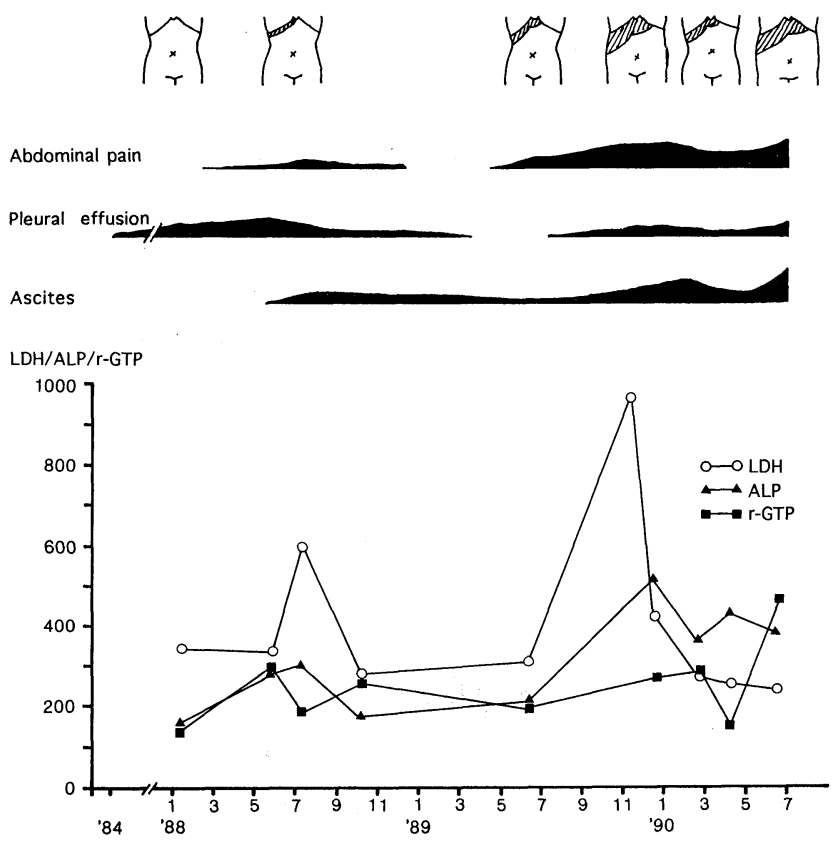

Fig. 4. Results of the liver function tests and major symptoms during treatment with prednisolone are diagrammed schematically. The intravenous infusions of methylprednisolone, 1,000 mg, are indicated by arrows. Each arrow head indicates the date of the abdominal computed tomography and liver ultrasonography shown in Fig. 3.

A thymic carcinoid is usually accompanied by multiple metastases $(1-3,5,7)$ that are often widespread, involving the skin, bones, lymphonodi, adrenal glands and liver. Recurrence or metastasis has been observed up to 18 years after the initial treatment $(1,4,5,7,8)$. Surgery, including the initial excision of the tumor and any recurrences, is the treatment of choice (5, 6). Postoperative chemotherapy with antineoplastic drugs has been administered; however, its efficacy is uncertain (5). In addition to the usual side effects of chemotherapy, patients with carcinoid symptoms show exacerbation of the syndrome after chemotherapy (9-12). Radiation therapy is generally recommended (4). In the present patient, no metastasis was found in the area to which radiation had been applied; therefore, we conclude radiation was highly effective in preventing recurrence at that site. Several authors have reported that prednisolone appears to improve carcinoid symptoms (12-14). In the chemotherapy of acute lymphocytic leukemia and lymphoma, glucocorticoids are used because of their antilymphocytic effects (15). Glucocorticoids also inhibit cell division or the synthesis of DNA in several tissues of laboratory animals (15). There were several reports that prednisolone was effective in preventing the growth of cerebral metastatic tumors of a bronchial carcinoid (16), primary malignant lymphoma of the central nervous system (17) and supratentorial intracranial tumors (18). The present patient's signs and symptoms were well controlled for 2 years and the mass size of the carcinoid was reduced by prednisolone. This steroid may, therefore, be useful in treating metastases from a thymic carcinoid. It may also be beneficial in patients who are not candidates for thymectomy.

\section{References}

1) Salyer WR, Salyer DC, Eggleston JC. Carcinoid tumors of the thymus. Cancer 37: 958, 1976.

2) Wick MR, Scott RE, Li C-Y, et al. Carcinoid tumors of the thymus: A clinicopathologic report of seven cases with a review of the literature. Mayo Clin Proc 55: 246, 1980.

3) Levine GD, Rosai J. Thymic hyperplasia and neoplasia: A review of current concepts. Hum Pathol 9: 495, 1978.

4) Economopoulos GC, Lewis JW Jr, Lee MW, et al. Carcinoid tumors of the thymus. Ann Thorac Surg 50: 58, 1990.

5) Akiyama $S$, Sakai $M$, Inoue $S$, et al. Thymic carcinoid-A case report and review of the literature. Jpn J Surg 20: 577, 1990.

6) Rosai J, Higa E. Mediastinal endocrine neoplasm, of probable thymic origin, related to carcinoid tumor: clinicopathologic study of 8 cases. Cancer 29: 1061, 1972.

7) Wick MR, Bernatz PE, Carney JA, et al. Primary mediastinal carcinoid tumors. Am J Surg Pathol 6: 195, 1982.

8) Hofman WJ, Herwart FO. Pathology of Tumors of the Thymic Region. in: Thoracic Surgery: Frontiers and Uncommon Neoplasms, vol 5. Martini N, Vogt Moykopf I, Eds. CV Mosby, St. Louis, 1988, p.166.

9) Mengel CE. Therapy of the malignant carcinoid syndrome. Ann Intern Med 62: 587, 1965.

10) Moertel CG. Clinical management of advanced gastrointestinal cancer. Cancer 36: 675, 1975.

11) Martin RG. Management of carcinoid tumors. Cancer 26: 547, 1970.

12) Bonomi P, Hovey C, Dainauskas JR, et al. Management of carcinoid syndrome. Med Pediatr Oncol 6: 77, 1979.

13) Ureles AL, Murray M, Wolf R. Results of pharmacologic treatment in the malignant carcinoid syndrome. N Engl J Med 267: 435, 1962.

14) Gailitis RJ, Scheiber W. Malignant carcinoid syndrome and latest concepts in serotonin metabolism. Am J Surg 99: 84, 1960.

15) Haynes RC Jr. Adrenocorticotropic Hormone; Adrenocortical Steroids and their Synthetic Analogs; Inhibitors of the Synthesis and Actions of Adrenocortical Hormones. in: Goodman and Gilman's the Pharmacological Basis of Therapeutics, Gilman AG, Rall TW, Nies AS, Taylor P, Eds. Pergamon Press, New York, 1990, p.1431.

16) Ohnsmann A, Sachsenheimer W. Intrazerebrale Metastasierung eines Bronchuskarzinoids. Neurochirurgia 35: 160, 1992.

17) Singh A, Strobos RJ, Singh BM, et al. Steroid-induced remissions in CNS lymphoma. Neurology 32: 1267, 1982.

18) Leiguarda R, Sierra J, Pardal C, et al. Effect of large doses of methylprednisolone on supratentorial intracranial tumors. A clinical and CAT scan evaluation. Eur Neurol 24: 23, 1985. 